\title{
Vaccination Perceptions of Urban School Employees
}

Janelle L. B. Macintosh

Brigham Young University - Provo, janelle-macintosh@byu.edu

Karlen E. Luthy

Brigham Young University - Provo

Katreena C. Merrill

Brigham Young University - Provo

Renea L. Beckstrand

Brigham Young University - Provo

Lacey M. Eden

Brigham Young University - Provo

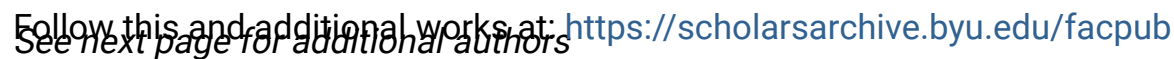

Part of the Other Nursing Commons

\section{Original Publication Citation}

Macintosh, J. L. B., Luthy, K. E., Merrill, K. C., Beckstrand, R. L., Eden, L. M., \& Wright, E. L.*(2016). Vaccination perceptions of urban school employees. Journal for Nurse Practitioners, 12(7), 438-444.

\section{BYU ScholarsArchive Citation}

Macintosh, Janelle L. B.; Luthy, Karlen E.; Merrill, Katreena C.; Beckstrand, Renea L.; Eden, Lacey M.; and Wright, Emily L., "Vaccination Perceptions of Urban School Employees" (2016). Faculty Publications. 5198. https://scholarsarchive.byu.edu/facpub/5198 accepted for inclusion in Faculty Publications by an authorized administrator of BYU ScholarsArchive. For more information, please contact ellen_amatangelo@byu.edu. 
Authors

Janelle L. B. Macintosh, Karlen E. Luthy, Katreena C. Merrill, Renea L. Beckstrand, Lacey M. Eden, and Emily L. Wright

This peer-reviewed article is available at BYU ScholarsArchive: https://scholarsarchive.byu.edu/facpub/5198 


\section{Vaccination Perceptions of Urban School Employees \\ Janelle L.B. Macintosh, PhD, RN, Karlen E. Luthy, DNP, FNP, Katreena C. Merrill, PhD, RN, Renea L. Beckstrand, PhD, RN, Lacey M. Eden, MS, FNP, and Emily L. Wright, BS, RN}

\section{ABSTRACT}

The purpose of this study was to explore public school employee perceptions regarding vaccinations. Employees from 1 urban school district in Utah responded to the School Employees' Perception of Immunizations Questionnaire. Lack of perceived efficacy was the most common explanation for lack of seasonal influenza vaccine. Being unsure of need was the most common reason participants were unvaccinated for measles, mumps, and rubella. The most common reason for rejecting a mandatory vaccine policy was a perceived violation of personal freedoms. Nurse practitioners can positively influence the health of public school employees by ensuring they are properly vaccinated.

Keywords: adults, immunization, school, vaccine

(C) 2016 Elsevier Inc. All rights reserved.

$\mathrm{F}$ ew medical advances have had a more positive influence on the health and wellness of

humans than vaccinations, which are proven to control the spread of life-threatening communicable diseases in communities. Although childhood vaccination rates in the United States have reached $90 \%,{ }^{1}$ vaccination rates vary widely. For example, the 2-dose measles, mumps, and rubella (MMR) vaccination rate upon entry to kindergarten was $99.9 \%$ in Mississippi and only $85.7 \%$ in Colorado. ${ }^{2}$ In contrast, adult vaccination coverage in the US remains low for most vaccines and is well below the Healthy People 2020 goals. $^{3}$

Highly virulent vaccine-preventable diseases (VPDs) require high vaccination rates in order to maintain healthy herd immunity. For example, influenza requires $80 \%$ of healthy persons and $90 \%$ of high-risk patients to be vaccinated each year in order to maintain adequate herd immunity. ${ }^{4}$ However, in 2015 , only $29.6 \%$ of adults aged 18 to 49 years updated their influenza vaccination during the 2015 season. ${ }^{5}$ Highly virulent diseases, such as measles, require $95 \%$ of the population to be fully vaccinated with the MMR vaccine in order to maintain herd immunity. ${ }^{6}$ Despite its importance, 1 of every 12 children in the US does not receive the MMR vaccine on time. ${ }^{1}$ There are no available data regarding adult MMR vaccination rates.

Nurse practitioners (NPs), like all health care providers (HCPs), are in an influential position where they can improve vaccination rates and help facilitate healthy herd immunity in communities. To positively influence vaccination rates, HCPs should routinely assess the vaccination status of all patients to ensure they are up-to-date. Reviewing and updating a child's vaccinations may be easier because children have more frequent health care visits that coincide with the childhood vaccination schedule and must be fully vaccinated before entering public school. In contrast, adult vaccination coverage is suboptimal, perhaps because they visit HCPs less often, are not subject to mandatory vaccination requirements, or work in environments in which vaccination policies are not enforced. When adults see their HCPs, missed opportunities to update necessary vaccinations during the visit are common. ${ }^{7}$ HCPs should recognize which patients are at risk for developing VPDs and use clinic opportunities to educate adult patients on the importance of vaccinations.

Adult patient education regarding vaccines should include information about environments that contribute to preventable disease outbreaks. The 
school is one such environment wherein communicable diseases quickly spread. Schools provide an ideal environment for disease outbreak because of many factors such as confined environments; dense populations; and frequent personal and close contact among students, faculty, and staff. ${ }^{8}$ Although vaccination requirements for school-age children are state legislated and regularly evaluated to maintain compliance, ${ }^{9}$ very little is known about the vaccination status of adult school employees who are also subject to communicable diseases in the school environment.

Currently, recommendations for verification of vaccination status in adult school employees are determined by individual states. For example, the Utah Department of Health ${ }^{10}$ recommends that all Utah school employees show proof of current vaccination records before employment, although this recommendation is not monitored. Therefore, the purposes of this study were to 1) identify the Utah adult school employee self-reported vaccination status for influenza and MMR, 2) explore the influenza and MMR vaccine perceptions of Utah adult school employees, and 3) to identify why Utah adult school employees may be opposed to a vaccination mandate similar to what is already required of schoolage children.

The following research questions were addressed:

1. What is the self-reported vaccination status of urban Utah school employees for influenza and MMR?

2. What are the perceptions about the seasonal influenza vaccine of urban Utah school employees who are not current on their influenza vaccine?

3. What are the perceptions of urban Utah school employees about the MMR vaccine for those who have not received an MMR booster vaccination as an adult?

4. What are the reasons for opposing mandated school employee vaccination policies of urban Utah school employees?

\section{METHODS}

\section{Sample}

A convenience sample of 1,400 public school employees was randomly selected from schools located in a Utah urban school district in northern Utah. The urban school district is comprised of 59 elementary, 16 junior high, and 8 senior high schools. Participants needed to work part-time or full-time at a school within the district or in the district office. Nonpaid personnel, such as volunteers and classroom aides, were excluded from this study. Although randomly selected as a participatory school, 2 of the elementary school principals declined to have their faculty and staff participate even though the study was approved by the district's assessment, research, and evaluation director. Thus, the sample decreased to 1,259 , representing 18 elementary schools, 6 district offices, 4 junior high schools, and 2 senior high schools.

\section{Instrument}

The School Employees' Perception of Immunizations Questionnaire has been used in previous studies among rural and urban school employees in Utah. ${ }^{11,12}$ Face validity of the instrument was established by a team of vaccination, public health, and nursing experts. The original 2-page anonymous questionnaire included 26 questions: 10 yes/no, 7 multiple-choice, 2 open-ended, and 7 demographic questions. ${ }^{11}$ This article will report on data from 2 multiple-choice and 2 open-ended questions. The demographic data were previously published ${ }^{12}$ but will be included in this article because the information still reflects the demographic characteristics of participants.

Responses to all other questions have been previously published. $^{12}$

Multiple-choice questions were used to explore the school employee's perceptions of vaccination. Participants who were not current on seasonal influenza and MMR could select the reason for being undervaccinated by marking options from a mark all that apply list for each vaccination. The list included an other option to allow participants to write in reasons for not receiving the seasonal influenza or MMR booster vaccinations, respectively.

The first open-ended question allowed public school employees to explain why they would be in opposition to a mandatory vaccination policy similar to the vaccination mandates of school children. The final open-ended question invited participants to write any additional comments regarding vaccines. 
The 7 demographic questions, which were previously published, ${ }^{12}$ included questions regarding sex, age, ethnicity, employment status (such as full-time vs part-time), and years worked in the school district. Additionally, participants were asked to identify in which type of school they were employed (such as elementary, junior high, or senior high school or the district office), as well as their current occupation.

\section{Procedure}

The institutional review board and the school district's director of assessment, research, and evaluation approved this project before data collection. The director and each of the principals and secretaries in the district were contacted via e-mail to inform them of the study. After the initial contact, questionnaires were distributed to each school along with directions for secretaries to place a packet in the mailbox of fulltime and part-time teachers and staff. School secretaries were asked to e-mail potential participants to notify them of the packet in their mailbox. A $\$ 1.00$ bill was provided in each packet for participants as an incentive, regardless of participation. Participants were asked to return the questionnaire in the envelope provided, whether it was completely filled out or if a participant did not wish to participate. Informed consent was implied if the employee returned the completed questionnaire.

\section{Data Analysis}

This article presents data gathered from the multiplechoice questions regarding the rationale for not being current with the influenza or MMR vaccine, the open-ended question allowing public school employees to explain why they did not believe adult school employees should have mandatory vaccine requirements, and the open-ended question inviting participants to make additional comments. The remaining data from the questionnaire, as well as the demographic data, have been published separately. ${ }^{12}$

Survey responses were entered into SPSS 19 (SPSS Inc, Chicago, IL). Once entered, the data were checked for accuracy by 2 separate researchers. The researchers alternated between reading the marked responses from each questionnaire and verifying that data were entered correctly. Responses to open-ended questions were analyzed using in vivo and open coding. Codes were then grouped into themes.

According to adult vaccination recommendations, as published by the Centers for Disease Control and Prevention, adults born before 1957 do not need a second MMR or a booster during adulthood because immunity is assumed. Therefore, when reporting data regarding reasons why the school employee had not received a second MMR vaccine, data on participants born before 1957 were not included.

\section{RESULTS}

Of the 1,259 questionnaires distributed, 852 were returned for a response rate of $67 \%$. Although overall demographics were published in a separate article, ${ }^{12} \mathrm{a}$ brief summary is included for description of the population characteristics.

The majority of participants were women $(\mathrm{n}=695,84.5 \%)$. Participants ranged in age from 22 to 78 years, with a mean of 46 years (standard deviation $=11.32$ ). Length of employment in the school district ranged from 1 to 55 years, with a mean of 12.91 years (standard deviation $=8.96$ ). The majority of participants were white $(n=780,96.2 \%)$, worked full-time $(\mathrm{n}=710,85.7 \%)$, were employed as teachers $(\mathrm{n}=550,66.4 \%)$, and were exclusively employed in an elementary school $(\mathrm{n}=475,57.6 \%) .{ }^{13}$

\section{Current Vaccination Status}

Influenza. There were 522 participants who explained why they had not received the influenza vaccine. The most frequently occurring response regarding why the employee had not received the seasonal influenza vaccine was he or she "didn't believe the vaccination would help" ( $\mathrm{n}=107$, $20.5 \%$ ). The second most frequently selected response for not receiving the seasonal influenza vaccine was that they "didn't have time [or] forgot ( $\mathrm{n}=84,16.1 \%)$. Other responses included "I am in good health and don't need it" ( $\mathrm{n}=83,15.9 \%)$, "[the vaccination] makes me sick" ( $\mathrm{n}=82,15.7 \%)$, "worried about vaccine side effects" ( $\mathrm{n}=74,14.2 \%)$, and "not required by my employer" ( $\mathrm{n}=35,6.7 \%)$. The responses "wasn't sure if I needed to get one," "cost," "vaccination-caused pain," and "allergic" collectively accounted for 54 responses, or $10.2 \%$. 
There were 223 participants who opted to use the other option for why they were unvaccinated against influenza. Of those who responded, approximately half $(n=106,45.5 \%)$ of the participants reported a specific date, location, or school fair in the future where they planned on receiving the seasonal influenza vaccine. Additionally, 45 (20.2\%) respondents reported a plan to receive the seasonal influenza vaccination but did not provide specific information about their plans.

MMR. There were 326 respondents who were eligible for a second MMR, meaning they were born in 1957 or later. Of these 326 respondents who provided reasons for why they had not received a second MMR vaccination or an MMR vaccination as an adult, the most common response reflected that employees were not sure they needed a second MMR vaccination $(\mathrm{n}=225,69 \%)$. Other less frequent responses included "didn't have time [or] forgot" ( $n=26,9 \%)$, "I am in good health and don't need it" ( $\mathrm{n}=22,6.7 \%)$, "not required by my employer" ( $\mathrm{n}=16,5 \%)$, and "didn't believe the vaccination would help" ( $\mathrm{n}=13,4 \%)$. Collectively, all remaining answers accounted for 23 (7.3\%) responses including "vaccination-caused pain" $(\mathrm{n}=9$, $2.8 \%)$, "worried about side effects" ( $\mathrm{n}=7,2.1 \%)$, "cost" ( $\mathrm{n}=3,0.9 \%)$, "[the vaccination] makes me sick" ( $\mathrm{n}=3,0.9 \%)$, and "allergic" $(\mathrm{n}=2,0.6 \%)$.

\section{Mandatory Vaccination}

Those who opposed a vaccination mandate for school employees were asked to share their thoughts by answering the open-ended question, "If not, why would you not want adult immunizations to be mandatory for school employees?" There were 643 (75\%) participants who wrote in responses.

Responses were coded into themes. The most commonly occurring $(n=117)$ responses dealt with the theme of freedom of choice. Participants reported that mandatory vaccinations violated personal choice. As 1 participant reported, "[mandatory vaccination] takes away my freedom to make decisions about my own health." This theme is further exemplified in comments such as "adults should be able to choose if they want to risk becoming sick" and "because it should be my choice. They should not force me to take any medication or get a vaccine if I don't want to. I know there is a risk I could get the flu."

The second most commonly occurring theme centered on the need for exceptions. Reponses $(n=22)$ focused on the need to be flexible and consider personal information. Reponses such as "some people cannot have them," "because of religious convictions or health reasons," and "I believe that there should be exemptions just as there are for children" are quotes from participants that exemplify this theme. A limited number of participants $(n=8)$ also commented that if someone else would carry the burden of cost they would not be opposed to mandatory vaccinations.

\section{Additional Insights}

Additionally, participants were given the opportunity to offer comments about the survey experience. There were 2 main insights that emerged: 1) participants reported an increased awareness of their personal vaccination status exemplified by comments such as "This made me think about talking to my [health care provider] about these issues," "I was unaware of an MMR booster. I am going to go do some research on that one," and "[Now] I am going to check my MMR and vaccine status" and 2) participants wanted additional information on adult vaccinations. This insight was exemplified by comments such as "What adult immunizations are needed? Send the school adult info," "I think adults need to be more informed about immunizations for adults," and "Adults need more education on immunizations that are appropriate for them."

\section{DISCUSSION}

Vaccinations are recommended throughout the life span to help prevent the spread of communicable diseases. Although high vaccination rates are an important part of preventing infectious diseases in any community, some communities struggle with maintaining high childhood vaccination rates, and adult vaccination rates are suboptimal in the general US population. ${ }^{13}$ Although a school may only be categorized as a small community, unvaccinated members of the school community have the potential to quickly spread VPDs throughout the community 
at large. In fact, the school community can quickly emerge as an outbreak center for VPDs, thus affecting others beyond the school environment. ${ }^{13}$ Therefore, vaccination of all members of the school community should be a priority for the HCP.

\section{Influenza}

Less than half of American children and less than one third of American adults received the influenza vaccination last year. ${ }^{5}$ There are several reasons for poor seasonal flu vaccination. ${ }^{14}$ In this sample, the most common reasons included disbelief in the helpfulness of the vaccine, forgetting or not having time, a belief that if a person is healthy he or she can overcome the influenza disease, and worrying about vaccine side effects. Each of these reasons is commonly used to justify not receiving a seasonal influenza vaccination. ${ }^{15}$

\section{MMR}

Approximately one third of parents (with children 0-13 years of age) regard measles as a harmless disease, and one quarter of adults 16 to 44 years of age do not believe that vaccination against measles is important. ${ }^{16}$ Gaczkowska et $\mathrm{al}^{16}$ reported that $81 \%$ of their participants who were born after 1970 did not know about the current guidelines for measles vaccination. Overwhelmingly, the most common reason given for not receiving an MMR booster in this study was that participants were not sure if they needed one. This response shows an obvious lack of knowledge regarding the MMR vaccine and the recommendations for adult vaccinations published by the Centers for Disease Control and Prevention. However, HCPs are in a pivotal position to provide measles vaccine education to their patients and, as a result, improve knowledge and uptake of MMR.

\section{Mandatory Vaccinations}

Previous research on attitudes of mandatory vaccination policies for adult employees has focused on specific populations, such as health care workers. A study of health care workers showed that two thirds of employees agreed with mandatory vaccinations. ${ }^{17}$ Macintosh et $\mathrm{al}^{17}$ studied school employees and found that only half of adult school employees believed they should be subject to a mandatory vaccination policy, although the presence of such a policy could deter costly school outbreaks of VPDs such as influenza and measles. For example, during a VPD outbreak, mandatory and recorded vaccinations of school employees may save school districts thousands of dollars ${ }^{18}$ because there would be no need to pay unvaccinated and quarantined full-time teachers and substitute teachers simultaneously. Additional research is needed to determine best practices for instituting mandatory vaccination policies for adult school employees.

\section{Implications for NPs}

HCPs are a trusted resource for vaccine information and are highly influential in improving uptake of vaccines. ${ }^{19}$ There is a need for NPs to fully promote vaccinations within their patient populations, including those who frequent the school environment, both children and adults alike. Providing patient education regarding the influenza and MMR vaccines is particularly important because these diseases are highly virulent and easily spread in the school environment. NPs should be prepared to address the common reasons patients refuse the influenza vaccine in particular. Excellent, no-cost educational resources regarding influenza vaccine are available at www.cdc.gov/vaccines/ed/patient-ed .htm, including fact sheets, answers to frequently asked questions, and flyers.

The most common reason for noncompliance with MMR in this study was that adults were unsure if they needed a second MMR vaccine. Screening patients and evaluating their vaccination status during every clinic visit provides opportunities for the NP to update MMR for adults, as well as all patient vaccinations. Support staff, when properly trained, can help the NP by evaluating patient vaccination records and identifying which vaccines are needed while checking the patient in. There is also evidence that using a reminder system or provider prompt to assess vaccination status as part of an electronic health record assists in timely completion of patient vaccines. ${ }^{20}$ For smaller clinics with concerns regarding their stock of vaccinations expiring before use, the NP may want to encourage all HCPs in the clinic to promote 1 adult vaccination per month, screening all 
patients for that particular vaccination and thus using the vaccine stock before it can expire.

NPs can be instrumental in promoting adult vaccinations in the school employee population, especially when partnered with school nurses who are already familiar with the population. With this partnership, NPs can assist with vaccination education during school staff meetings, using data to foster school employee vaccination knowledge. NPs can also work with school nurses to schedule on-site vaccination clinics during school employee lunch breaks or after school. Additionally, NPs may want to recommend technologic resources freely available to school employees to track vaccinations. Most states already have a functioning immunization information system that records and tracks vaccinations, and over $90 \%$ of immunization information systems have a reminder and recall notification feature. ${ }^{21}$ School employees should be aware of such resources.

\section{Limitations}

The use of 1 school district in 1 state may not represent the population of school employees. The findings of this study might not apply to school employees working in other communities. Additionally, only paid school employees were eligible for participation in this study; findings from this study may not be generalizable to nonpaid personnel such as volunteers. Finally, the participants in this study were all employees of a public school district, and their ideas might not accurately represent employees of charter or private schools.

\section{CONCLUSIONS}

Adequate vaccination is an important contributor to the overall health of a community. Many adults are not adequately vaccinated, although adults in a school environment may be at higher risk for contracting and spreading VPDs and, therefore, should have their vaccination status evaluated regularly by the NP. Participants in this study showed a need for education about required vaccinations, as well as the potential health benefits. NPs are in a prime position to promote adult vaccination compliance and can share strategies to improve adult vaccination rates. $\mathbb{N \mathbb { N P }}$

\section{References}

1. Elam-Evans LD, Yankey D, Singleton JA, et al. National, state, and selected local area vaccination coverage among children aged 19-35 months-United States, 2013. MMWR Morb Mortal Wkly Rep. 2014;63(34):741-748.

2. Seither R, Shaw L, Knighton CL, Greby SM, Stokley S. Immunization Services Division, National Center for Immunization and Respiratory Diseases, \& Centers for Disease Control and Prevention. Vaccination coverage among children in kindergarten-United States, 2012-2013 school year. MMWR Morb Mortal Wkly Rep. 2013;62(30):607-612.

3. Williams WW, Lu PJ, O'Halloran A, et al. Noninfluenza vaccination coverage among adults-United States, 2012. MMWR Morb Mortal Wkly Rep. 2014;63(5):95-102.

4. Plans-Rubio P. The vaccination coverage required to establish herd immunity against influenza viruses. Prev Med. 2012;55(1):72-77.

5. Centers for Disease Control and Prevention. Influenza. www.cdc.gov/nchs/ fastats/flu.htm. Published January, 27 2013. Accessed January 21, 2016.

6. Oxford Vaccination Group. Herd immunity. www.ovg.ox.ac.uk/herd -immunity. Published November 16, 2015. Accessed January 21, 2016.

7. Swenson CJ, Appel A, Sheehan M, et al. Using information technology to improve adult immunization delivery in an integrated urban health system. Jt Comm J Qual Patient Saf. 2012;38(1):15-23.

8. Gargano LM, Pazol K, Sales JM, et al. Multicomponent interventions to enhance influenza vaccine delivery to adolescents. Pediatrics. 2011;128(5): e1092-e1099.

9. State vaccination requirements. Centers for Disease Control and Prevention website. http://www.cdc.gov/vaccines/imz-managers/laws/state-reqs.html. Updated September 30, 2011. Accessed January 21, 2016.

10. Utah school and childcare employee immunization recommendations. Utah Department of Health Website. http://www.immunize-utah.org/pdf/Utah_ School_Childcare_Employee_Imm_Rec.pdf. Published July 2011. Accessed January 21, 2016.

11. Luthy KE, Houle K, Beckstrand RL, Macintosh J, Lakin RG. Vaccine perceptions and barriers of school employees: a pilot study. J Sch Nurs. 2013;29(4):184-193.

12. Luthy KE, Thompson KE, Beckstrand RL, Macintosh JLB, Eden LM. Perception of safety, importance, and effectiveness of vaccinations among urban school employees in Utah. J Am Assoc Nurse Pract. 2015;27(6):313-320.

13. De Perio MA, Wiegand DM, Brueck SE. Influenza vaccination coverage among school employees: assessing knowledge, attitudes, and behaviors. J Sch Health. 2014;84(9):586-592.

14. Wheelock A, Thomson A, Sevdalis N. Social and psychological factors underlying adult vaccination behavior: lessons from seasonal influenza vaccination in the US and the UK. Expert Rev Vaccines. 2013;12(8):893-901.

15. Ernsting A, Schwarzer R, Lippke S, Schneider M. 'I do not need a flu shot because I lead a healthy lifestyle': compensatory health beliefs make vaccination less likely. J Health Psychol. 2013;18(6):825-836.

16. Gaczkowska A, Mertens B, Reckendrees B, Wortberg S, Pott E. [Knowledge, attitude, and practice concerning measles vaccination. Approaches for national vaccination education]. Bundesgesundheitsblatt Gesundheitsforschung Gesundheitsschutz. 2013;56(9):1270-1278.

17. Macintosh JLB, Luthy KE, Beckstrand RL, Eden LM, Orton J. Vaccination perceptions of school employees in a rural school district. Vaccine. 2014;32(37):4766-4771.

18. Stewart K. Measles outbreak linked to returned missionary's family. Salt Lake Tribune. April 14, 2011. http://www.sltrib.com/sltrib/news/ 51614160-78/measles-health-virus-parents.html.csp. Accessed January 21, 2016.

19. Centers for Disease Control and Prevention. Adult vaccination information for healthcare and public health professionals. www.cdc.gov/vaccines/hcp/ patient-ed/adults/index.html. Published February 10, 2014. Accessed January 21, 2016.

20. Ruffin MT, Plegue MA, Rockwell PG, Young AP, Patel DA, Yeazel MW. Impact of an electronic health record (EHR) reminder on human papillomavirus (HPV) vaccine initiation and timely completion. J Am Board Fam Med. 2015;28(3): 324-333.

21. Centers for Disease Control and Prevention. Progress in immunization information systems-United States, 2012. MMWR Morb Mortal Wkly Rep. 2013;62(49):1005-1008.

All authors are affiliated with Brigham Young University in Provo, UT. Janelle L.B. Macintosh, PhD, RN, is an assistant professor. Karlen E. Luthy, DNP, FNP, is an associate professor 
and can be reached at beth_luthy@byu.edu. Katreena C.

Merrill, PhD, RN, is an assistant professor. Renea $L$.

Beckstrand, PhD, RN, is a professor. Lacey M. Eden, MS, $F N P$, is an assistant teaching professor. Emily L. Wright, BS, $R N$, is in London. In compliance with national ethical guidelines, the authors report no relationships with business or industry that would pose a conflict of interest.

\section{Acknowledgments}

Supported by the Lewis Family Foundation. The authors would like to express their gratitude to the Lewis Family Foundation whose research grant made this study possible.

$1555-4155 / 16 / \$$ see front matter

(C) 2016 Elsevier Inc. All rights reserved.

http://dx.doi.org/10.1016/j.nurpra.2016.05.014

\section{Erratum}

In the article "A Nurse Practitioner-Led Intervention to Reduce Hospital Readmissions" (May 2016), an error was noticed in the third column heading of Table 2. The correct column heading is "Eligible but no PACT Visit (Control) $(n=144)$ ". The online version of the article has been corrected. 